\title{
Solar radiation plays a role in habitat selection by the sea star Pisaster ochraceus
}

\author{
Jennifer L. Burnaford ${ }^{1, *}$, Melissa Vasquez ${ }^{1,2}$ \\ ${ }^{1}$ Department of Biology, University of Puget Sound, 1500 N. Warner Street \#1088, Tacoma, Washington 98416, USA \\ ${ }^{2}$ Present address: Duke University Marine Laboratory, Nicholas School of the Environment and Earth Sciences, \\ 135 Duke Marine Lab Road, Beaufort, North Carolina 28516-9721, USA
}

\begin{abstract}
In order to avoid intense abiotic stresses at low tide, motile animals in the intertidal zone must identify and move into 'safe' microhabitats before the tide drops. We experimentally investigated the role of solar radiation in the microhabitat selection of the sea star Pisaster ochraceus, an ecologically important predator in the Pacific Northwest. Specifically, we tested the response of $P$. ochraceus to UVB radiation (290 to $315 \mathrm{~nm}$ ), UVA radiation (315 to $400 \mathrm{~nm}$ ), and photosynthetically active radiation $\left(\mathrm{PAR}_{i} 400\right.$ to $700 \mathrm{~nm}$ ) to determine whether specific wavelength ranges prompted specific responses. Sea stars were exposed to ambient summer light levels in shallow water in outdoor aquaria in which one-half of the tank was covered with a light-filtering material. We established 4 light filtration treatments: filter control (+UVB +UVA +PAR), no UVB (-UVB +UVA +PAR), no UVR (-UVB -UVA +PAR), and shade (-UVB -UVA -PAR), plus a no-filter control treatment (+UVB +UVA + PAR). P. ochraceus did not avoid UVB or UVA, but they did avoid PAR: individuals in tanks with shaded areas spent significantly more time under the filters than did individuals in the tanks with filters that blocked UV radiation. In field surveys, $85 \%$ of emersed $P$. ochraceus encountered during low tide were located in areas completely shaded from both PAR and UV radiation (by rocks or by the intertidal kelp Hedophyllum sessile). This study demonstrates that the presence of PAR in shallow water conditions prompts $P$. ochraceus to seek out shaded microhabitats that have more benign lowtide abiotic conditions than exposed rock benches.
\end{abstract}

KEY WORDS: Habitat selection · Pisaster ochraceus $\cdot$ PAR $\cdot$ UV radiation

\section{INTRODUCTION}

The sea star Pisaster ochraceus is an ecologically important predator in the intertidal zone of the U.S. Pacific Northwest. On wave-exposed rocky shores, the sea star preys strongly on the mussel Mytilus californianus, increasing the diversity of the system by opening up space for the mussel's competitors (Paine 1966, Menge et al. 1994). Because of this strong interaction, P. ochraceus was the first species to be termed a keystone predator (Paine 1966). On wave-protected rocky shores, this sea star is a major predator of intertidal invertebrates such as chitons, limpets, and barnacles (Mauzey 1966, Menge 1972, Burnaford 2004), and the large size and mobility of adult $P$. ochraceus make it a very effective competitor against other sea stars in the system (Menge 1972). Across a spatially heterogeneous environment like the intertidal zone, the overall impact of a predator or competitor will be determined by the frequency with which it encounters a target species. The chance of encounter will be determined to some extent by the behavior of each species and their response to environmental stimuli. Because of the important role that $P$. ochraceus plays in intertidal communities, we were interested in determining the cues used by the sea star in choosing its microhabitat location within the intertidal zone.

Microhabitat location can be particularly important to intertidal organisms because of the challenges associated with exposure to terrestrial conditions at low 
tide. Solar radiation during low tide exposure can raise body temperatures of intertidal ectotherms more than $20^{\circ} \mathrm{C}$ above their temperatures at high tide (Helmuth \& Hofmann 2001, Burnaford 2004). Such large temperature fluctuations might affect water balance, metabolic rates, or protein structure (Helmuth \& Hofmann 2001). Solar radiation can also have direct effects on organisms. Photosynthetically active radiation (PAR; 400 to $700 \mathrm{~nm}$ ) is important for plant and algal photosynthesis, but high-intensity PAR can also cause damage to the photosynthetic apparatus (Lobban \& Harrison 1994). UV radiation (UVR; 290 to $400 \mathrm{~nm}$ ) has a number of biologically important effects on living organisms. UVR can directly damage DNA (Sinha \& Hader 2002, Hader \& Sinha 2005) and cause the production of reactive oxygen species which can in turn damage a number of molecules including proteins, membrane lipids, and chlorophyll (Lesser 2006). Studies on widely disparate taxa have shown significant negative effects of UVR on organisms around the globe (reviewed in Hader et al. 2007). Exposure of planktonic echinoid embryos and larvae to UVR has been demonstrated to cause DNA damage, abnormal development, and mortality (Lesser \& Barry 2003). Molluscan embryos laid in benthic egg masses also experience high mortality when exposed to UVR (Przeslawski et al. 2004). Subtidal kelps have shown reduced germination success (Hoffman et al. 2003) and photoinhibition (Apprill \& Lesser 2003) at ambient levels of UVR. There is also growing evidence that adult invertebrates can be damaged by UVR. The tropical brittlestar Ophioderma brevispinum experienced visible tissue damage and high rates of mortality when exposed to UVR for only $48 \mathrm{~h}$ in shallow water conditions (Johnsen \& Kier 1998). Skin tissues of tropical fish can be damaged by exposure to ambient levels of UVR (Zamzow 2004).

Given the potentially damaging effects of exposure to solar radiation during low tide, it seems likely that organisms with the ability to locate 'safe' or less stressful low-tide habitats would have lower levels of physiological stress and therefore higher levels of individual fitness than individuals that remained in less suitable habitats at low tide. In rocky intertidal areas, safe habitats might include spaces shaded by rocky overhangs or the canopies of fleshy algae or surfgrass. However, many intertidal organisms, including Pisaster ochraceus, are unable to change their location when they are not immersed in water. Therefore, safe low-tide habitats would need to be identified at high tide or as the tide goes out; this would best be accomplished by the use of a cue that reliably indicates low-tide conditions but can be detected underwater. Light is one possible cue that fits these criteria.

Animals from a number of taxonomic groups are known to use specific portions of the light spectrum as cues for movement and habitat selection. Coral larvae (Gleason et al. 2006), Antarctic krill (Newman et al. 2003), freshwater cladocerans (Leech \& Williamson 2001), juvenile salmon (Kelly \& Bothwell 2002), and adult sea urchins (Adams 2001, Verling et al. 2002) have all been shown to specifically avoid UVR. The transmission of light through the water column can change on small and large time scales as a consequence of changes in the concentration of dissolved organic matter or phytoplankton (Xenopoulos \& Schindler 2001), and therefore the amount of light that can be detected by benthic organisms at high tide varies over time. However, when low tides fall during daylight hours, the change in solar exposure as the tides cycle should be predictable for intertidal organisms. As water levels drop with the falling tide, animals that are not in a shaded habitat are covered by an increasingly small layer of water with, presumably, increasingly high intensities of radiation of all wavelengths, until they are exposed to high-intensity solar radiation at low tide.

To investigate the potential cues used by the sea star Pisaster ochraceus to select low-tide location, we recorded the behavioral response of individuals when exposed to different ranges of the light spectrum while covered with a shallow layer of water to reflect the conditions of a dropping tide. Both PAR and UVR are potential cues for habitat selection under these conditions as they both penetrate coastal waters, although UVR is attenuated more rapidly than PAR with increasing depth (Tedetti \& Sempere 2006). Levels of UVR equivalent to $10 \%$ of surface intensities have been shown to $22 \mathrm{~m}$ depth for UVA (315 to $400 \mathrm{~nm}$ ) and $5 \mathrm{~m}$ for UVB (290 to $315 \mathrm{~nm}$ ) (Tedetti \& Sempere 2006). We conducted a series of experiments to determine whether $P$. ochraceus could detect light in the UV spectrum and whether it used this information to select low-UVR microhabitats. We also conducted field surveys to determine whether individuals were found in low-UVR microhabitats during low tide in the field.

\section{MATERIALS AND METHODS}

Animal collection and care. We collected Pisaster ochraceus during low tides from Eastsound, Orcas Island, Washington, USA ( $48^{\circ} 37^{\prime} 33.2^{\prime \prime} \mathrm{N}, 122^{\circ} 52^{\prime} 38.0^{\prime \prime} \mathrm{W}$ ). Sea stars were maintained at ambient water temperatures in flow-through seawater tanks at Friday Harbor Laboratories (FHL), Friday Harbor, San Juan Island, Washington. Holding tanks were located out of direct sunlight but experienced ambient day/night light cycles. We provided 2 to 3 clams (Nuttallia obscurata) per sea star every 5 to $8 \mathrm{~d}$. Sea stars were held for no more than $12 \mathrm{~d}$ before use in experiments, and each 
individual was only used once. The average $\pm \mathrm{SD}$ arm length of experimental sea stars (measured from center of central disc to tip of arm) was $14.79 \pm 1.67 \mathrm{~cm}$.

We tested the effect of hunger on response to UVR by establishing 2 different pre-experiment feeding treatments. In 2005 we fed sea stars $24 \mathrm{~h}$ before the start of an experimental trial. Because hungry individuals might be more likely to explore their environment (to search for food) than satiated individuals, we repeated the experiment in 2006 with a different feeding protocol in which sea stars were last fed $72 \mathrm{~h}$ before the start of an experimental trial.

Experimental design. We conducted experiments outdoors at FHL to test the response of sea stars to ambient summer light conditions. Experimental trials were conducted from 10:00 to 14:00 h on clear, sunny days in July and August 2005 and July 2006. Summer low tides that expose Pisaster ochraceus in this area occur between approximately 07:00 and 14:00 h. Therefore our experimental trials were carried out in naturally occurring radiation conditions at a realistic time of day.

Experiments were conducted in flow-through acrylic plastic (Plexiglas) seawater tanks $(60 \times 125 \times 28 \mathrm{~cm}$; Fig. 1). Because the sides of the experimental tanks filtered UVR, we placed sea stars on platforms that were installed at a depth of $7.5 \mathrm{~cm}$. The sides of the tanks did not cast shade onto the platforms. Water flowed up onto the platform from all sides and drained from the surface into the standpipe (Fig. 1).

To determine how different wavelengths of light affected sea star habitat choice, we established 5 experimental treatments with different combinations of UVB, UVA, and PAR. For the filter treatments (Treatments 2 to 5), one-half of the tank was covered with the

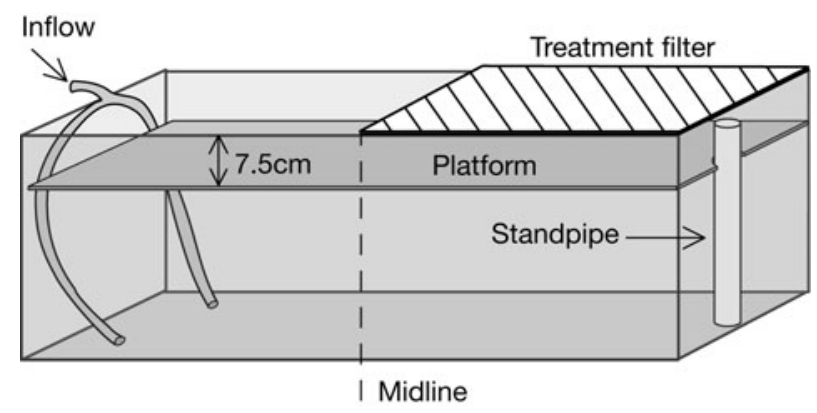

Fig. 1. Experimental tanks. Experiments were conducted in outdoor aquaria $(60 \times 125 \times 28 \mathrm{~cm})$. Water flowed into the tanks below the platform, up around the sides of the platform and out from the surface of the tank through the standpipe. Filters were placed over $50 \%$ of the top of the tank. At the start of the experiment individual sea stars were placed on platforms $7.5 \mathrm{~cm}$ below the surface of the water at the tank midline, with 2.5 arms under the treatment filter and 2.5 arms in the open (uncovered) portion of the tank light-filtering material and the other half was left uncovered and open to ambient light conditions (Fig. 1). Filters were suspended approximately $2 \mathrm{~cm}$ above the surface of the water and did not interfere with the movement of the sea stars. The placement of the filters on the tank (standpipe or water inflow side) was randomly determined separately for each replicate. The light transmission properties of filter materials were tested on multiple sunny days using a spectroradiometer (Li-1800UW, Li-Cor). The treatments were as follows:

(1) No-filter control: Tanks were completely exposed to ambient light (UVB, UVA, and PAR).

(2) Filter control: On one-half of the tank, a sheet of $3.5 \mathrm{~mm}$ acrylic plastic (Acrylite OP4) transmitted $>80 \%$ of UVB, UVA, and PAR (Fig. 2).

(3) No UVB: On one-half of the tank, a sheet of $0.1 \mathrm{~mm}$ polyester film (Mylar) prevented transmission of UVB but allowed transmission of UVA and PAR (Fig. 2).

(4) No UVR: On one-half of the tank, a piece of $3.5 \mathrm{~mm}$ polycarbonate sheeting (Makrolon) prevented

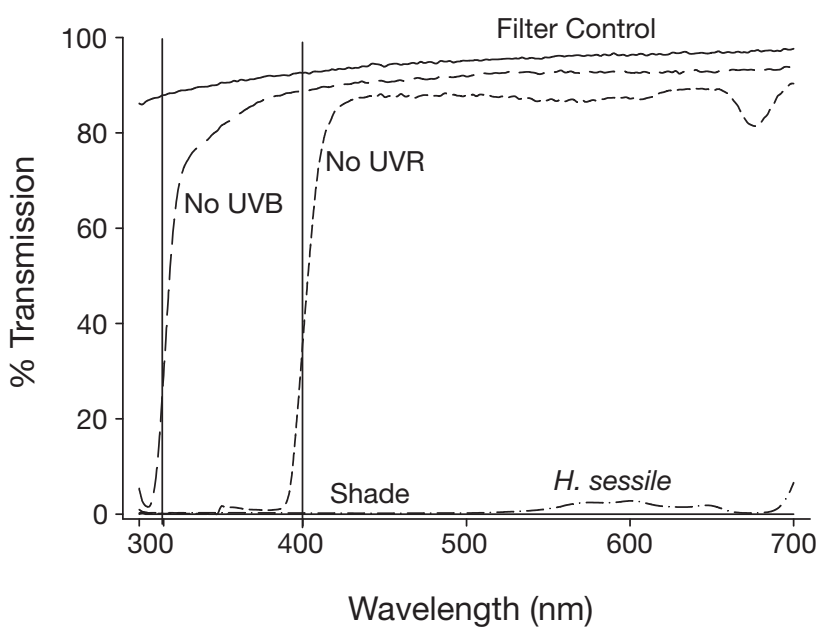

Fig. 2. Light conditions under experimental filters and algal canopies. Irradiance measurements were made by scanning at $2 \mathrm{~nm}$ intervals from 300 to $700 \mathrm{~nm}$ with a LiCor Li-1800UW spectroradiometer. Wavelength ranges that define UVB (up to $315 \mathrm{~nm}$ ), UVA (315 to $400 \mathrm{~nm}$ ), and PAR (400 to $700 \mathrm{~nm}$ ) are separated on the $x$-axis by vertical lines. Data are presented for each material as the \% of energy transmitted relative to full ambient summertime sunlight conditions at mid-day under cloudless skies. Because organisms in the no-filter control treatment were fully exposed to ambient conditions, that treatment is not represented. The filter control treatment material transmitted approximately evenly throughout the range of wavelengths tested. The no-UVB and no-UVR treatment materials removed UVB and UVB + UVA, respectively. The shade treatment material removed $100 \%$ of ambient solar radiation in the range tested. Hedophyllum sessile, the most abundant shade-producing alga in our field surveys, transmitted $<3 \%$ of radiation in most of the tested range 
transmission of UVB and UVA but allowed transmission of PAR (Fig. 2).

(5) Shade: On one-half of the tank, a piece of $0.2 \mathrm{~mm}$ black plastic prevented transmission of UVB, UVA, and PAR (Fig. 2).

The experimental array consisted of 10 identical tanks fed by a single water supply (from the FHL flowthrough seawater system). We consider an experimental block to be a $4 \mathrm{~h}$ experiment in which there were 2 replicate tanks of each of the 5 treatments. Each tank had a single sea star. Each block was run on a separate day. Treatments were randomly assigned to tanks; randomizations were conducted separately for each block. We ran 5 blocks of the experiment in 2005 (all with the $24 \mathrm{~h}$ feeding regime) and 5 blocks in 2006 (all with the $72 \mathrm{~h}$ feeding regime).

In 2006 we measured in situ spectral irradiance every 15 min during experiments by scanning with a spectroradiometer (Li-1800UW). Each scan collected measurements at $2 \mathrm{~nm}$ intervals from 300 to $700 \mathrm{~nm}$. Measurements were taken in air in an unshaded space $<1 \mathrm{~m}$ from the experimental tank array using a PTFE dome cosine collector with $180^{\circ}$ field of view. We calculated a single overall radiation exposure estimate for each scan by integrating the measurements over the entire wavelength range. We then averaged the values for each scan during a $4 \mathrm{~h}$ experimental trial to calculate a single average intensity of solar radiation on that day. We calculated separate intensity estimates for UVB and UVA by integrating the measurements for each scan over the appropriate wavelength range (300 to $315 \mathrm{~nm}$ for UVB, 315 to $398 \mathrm{~nm}$ for UVA) and then summing the values for all scans to get a total UVB or UVA exposure for the $4 \mathrm{~h}$ period.

The spectral properties of filter materials and environmentally relevant shade-producing objects (such as the kelp Hedophyllum sessile) were also measured using the LiCor spectroradiometer. We compared scans taken in full ambient sunlight conditions to scans taken $<1$ min later underneath treatment materials to determine the degree to which each material blocked solar radiation. We performed multiple scans on multiple cloudless days to provide replicate readings for each material.

During experiments in 2005 we recorded water temperature at $15 \mathrm{~min}$ intervals in 3 to 4 randomly chosen tanks per block using submersible dataloggers (Ibutton-TMX dataloggers, Dallas Semiconductor) placed in the center of the experimental platforms. In 2006 we measured tank temperatures every $25 \mathrm{~min}$ with standard alcohol thermometers. Water temperatures ranged from 12 to $14.5^{\circ} \mathrm{C}$, with a mean of $13.5^{\circ} \mathrm{C}$ in 2005 and $13.6^{\circ} \mathrm{C}$ in 2006 . Using data from 2006 we calculated the mean temperature (over $4 \mathrm{~h}$ ) for each tank ( $\mathrm{n}=10$ tanks block $^{-1}$ in 5 blocks) and compared treat- ments using an ANOVA with block and treatment as main effects. Although temperatures differed among blocks $(F=8.32, \mathrm{p}=0.0002)$, there was no detectable difference among treatments (treatment effect, $F=$ $1.11, \mathrm{p}=0.37$; block $\times$ treatment effect, $F=0.33, \mathrm{p}=$ 0.99).

To determine whether temperatures differed between the filter and no-filter sides of our tanks, we monitored temperatures on days that we were not running experiments in 2005 and 2006. At 10 min intervals, we simultaneously recorded temperatures on both sides of experimental tanks using dataloggers (Ibutton-TMX) placed in the center of the platforms. Temperatures were slightly lower under filters than in the open side of the tank, but the difference was $<1^{\circ} \mathrm{C}$. Mean temperature difference between the 2 sides was similar in the no-UVB and filter control tanks (no UVB: mean $\pm \mathrm{SD}, 0.23 \pm 0.36^{\circ} \mathrm{C}, \mathrm{n}=179$ measurements; filter control: mean $\pm \mathrm{SD}, 0.28 \pm 0.38^{\circ} \mathrm{C}, \mathrm{n}=129$ measurements). The difference in shade tanks (mean $\pm \mathrm{SD}$, $0.48 \pm 0.44^{\circ} \mathrm{C}, \mathrm{n}=153$ measurements) was similar to the difference in no-UVR tanks (mean \pm SD, $0.40 \pm$ $0.48^{\circ} \mathrm{C}, \mathrm{n}=163$ measurements).

Data collection and analysis. At the start of each experimental block, 1 individual was placed in each tank with 2.5 arms on each side of the tank midline (for filter treatments, this corresponded to 2.5 arms under the filter and 2.5 arms in the open). From 10:00 to 14:00 h, we recorded the position of all sea stars every 5 min. Recording the position of all 10 experimental individuals took $<1 \mathrm{~min}$. Observers did not cast shade on the tanks during data collection. In no-filter controls, position was recorded as 'water inflow' side, 'standpipe' side, or 'midline'. In treatment tanks, we recorded positions as 'under filter', 'in open', or as 'partially under filter' (if individuals only had some arms under the filter). This allowed us to make conservative estimates of the amount of time spent under filters because we could distinguish between partial and full filter conditions. This method of data collection also allowed us to assess the overall frequency of Pisaster ochraceus movement. For example: if an individual started under a filter, extended an arm beyond the edge of the filter at the tank midline, then reversed direction and pulled back under the filter, we counted this as 2 switches in position. We chose a 5 min data collection interval because preliminary experiments indicated that individuals did not make more than 1 location change in a $5 \mathrm{~min}$ period. We analyzed 2 response variables to quantify the effect of light treatments on sea star behavior: (1) first choice of microhabitat and (2) proportion of time spent by individuals fully under filters.

Response variable 1: first choice of microhabitat: Sea stars were placed in the center of the tank to start 
the experiment; therefore we counted their first-choice location as the side of the tank to which they moved when they left this starting position. We compared the response of the sea stars in the 2 feeding regimes using a chi-square test of independence. The first-choice locations did not differ between the 2 feeding regimes for any of the experimental treatments (all p > 0.12). Therefore, in further analysis of this response variable, data from the 2 feeding regimes were combined $(n=20$ sea stars per treatment). We used chi-square tests of independence (SPSS version 14.0) to compare the firstchoice locations for relevant pairs of treatments.

Response variable 2: proportion of time spent under filters: To examine whether the proportion of time spent under filters was affected by light treatment, we used the percent of observations in which individuals were fully under the filter as our response variable. For each tank of the no-filter control treatment, we randomly chose a side of the tank as our response side and counted the percentage of observations in which individuals were found on this side of the tank. In 1 block of the $24 \mathrm{~h}$ feeding regime, one of the no-filter control tanks lost structural integrity $80 \mathrm{~min}$ into the experiment. To maintain equal sample size for all treatments, we substituted the data from the other replicate of the treatment in the same block for analysis. Because the variance of the data was different in the 2 feeding regimes and data transformations could not make the data appropriate for a single ANOVA, we were unable to directly compare this response variable between the 2 feeding regimes. Therefore for this response variable we tested the 2 feeding regimes separately. The Kolmogorov-Smirnov test of normality and Levene's test of homogeneity of variance (both performed in SPSS version 14.0) showed that all assumptions of the ANOVA were met for untransformed data. We tested the effect of light treatment on microhabitat choice using 1-way ANOVA with block and treatment as main effects. When the overall treatment effect was significant, we examined the effect of specific wavelength ranges using pre-determined linear contrasts. To determine whether our treatment filters had an effect on sea star movement, we compared the response of individuals in no-filter controls (+UVB +UVA + PAR) to individuals in the filter control tanks (+UVB $+\mathrm{UVA}+\mathrm{PAR}$ ). To evaluate the response to UVB, we compared individuals in the no-UVB treatment (-UVB $+\mathrm{UVA}+\mathrm{PAR})$ to individuals in the filter control treatment (+UVB +UVA +PAR). To evaluate the response to UVA, we compared individuals in the no-UVR treatment (-UVB -UVA +PAR) to individuals in the noUVB treatment (-UVB +UVA +PAR). To evaluate the response to $\mathrm{PAR}$, we compared the response of individuals in the no-UVR treatment (-UVB -UVA +PAR) to individuals in the shade treatment (-UVB -UVA
-PAR). ANOVAs and contrasts were performed in JMP (version 4.04).

Because we had light intensity measurements for the 2006 experiments, we used a correlation analysis to determine whether there was a relationship between the time spent under filters by sea stars in the no-UVR and shade treatments and the total intensity of UVA or UVB during the experimental block. Correlation analysis was performed in SPSS (version 14.0).

Field surveys. To evaluate Pisaster ochraceus microhabitat choice under natural conditions, we monitored a population at Pile Point, San Juan Island, Washington $\left(48^{\circ} 29^{\prime} \mathrm{N}, 123^{\circ} 05^{\prime} \mathrm{W}\right)$. This is a moderately waveexposed site characterized by large patches of the alga Hedophyllum sessile (described in Burnaford 2004). We conducted low-tide field surveys on 15 separate days between 3 June and 4 August 2005. In each survey, we searched the exposed rocky bench area (approximately $1800 \mathrm{~m}^{2}$; the exact area depended on the tidal height at low tide) and we recorded the microhabitat location of all $P$. ochraceus. We categorized encountered individuals as entirely shaded (by rock, kelp, or seagrass), partially shaded, or entirely unshaded. We made 283 observations of individuals that were completely emersed at low tide and 91 observations of sea stars in tidepools or at the edge of the water line (covered by $<0.5 \mathrm{~m}$ of water).

We compared UVR conditions in different microhabitats using a UVX Radiometer and UVX-31 and UVX36 sensors (UVP). Because these sensors measure radiation of only a single wavelength $(310 \mathrm{~nm}$ in the UVB range and $365 \mathrm{~nm}$ in the UVA range), measurements were used to compare microhabitats and not to quantify absolute radiation levels.

\section{RESULTS}

\section{Microhabitat selection in tank experiments}

Thirty-nine percent of sea stars tested made their first microhabitat choice within 5 min of the start of the experiment. Only $7 \%$ of individuals took longer than 20 min to make their first choice. All sea stars changed position more than once during the $4 \mathrm{~h}$ experiment. There was no evidence that the experimental tank setup itself influenced first microhabitat choice: in the nofilter controls (+UVB +UVA +PAR), $50 \%$ of individuals (10 of the 20 individuals tested) moved to the inflow side of the tank and the other $50 \%$ moved to the standpipe side of the tank.

Light regime had a strong effect on first microhabitat choice. Individuals in the shade treatment (-UVB -UVA -PAR) showed a strong negative response to light: $100 \%$ of individuals moved directly underneath 
the shaded filter from their starting position in the center of the tank. Despite this strong response to full spectrum light, there was no detectable avoidance of UVA or UVB. In the filter control treatment (+UVB +UVA +PAR), $65 \%$ of individuals moved under the filter as they moved away from the midline, despite the fact that the control filters transmitted UVR. Only $25 \%$ of individuals in the no-UVB treatment (-UVB +UVA +PAR) moved under the filter from the center of the tank at the start of the experiment. In the no-UVR treatment (-UVB -UVA +PAR), $60 \%$ of individuals moved under the filter as they moved away from the midline; this was not significantly different from the $50 \%$ filter choice one would expect if the sea stars were moving randomly away from the midline (chi-square goodness of fit test, $\chi^{2}=0.80, p=0.371$ ). The response in the no-UVR treatment was significantly different from the response of the individuals in the shade treatment (chi-square test of independence: $\chi^{2}=10.00, p=0.002$ ). Taken together, these results suggest that Pisaster ochraceus respond negatively to ambient levels of PAR but not to ambient levels of UVA or UVB.

Analysis of the total amount of time spent in different microhabitats supports this conclusion. In both feeding regimes, sea star behavior was strongly affected by light treatment (Table 1 ; treatment effect, both $\mathrm{p} \leq 0.0003)$. Sea stars in the filter control treatment spent on average $<50 \%$ of their time in the filter side of the tank (Fig. 3), indicating that the presence of experimental filters did not affect behavior (Table 1 ; contrast 1 , effect of filter; both $p>0.25$ ). Sea stars did not respond specifically to the presence of UVB or UVA in either feeding regime. On average, individuals spent $<51 \%$ of their time under treatment filters in the filter control, no-UVB, and noUVR treatments (Fig. 3). Contrasts to determine the effect of UVB and UVA showed no significant difference among the behavior of sea stars in these treatments (Table 1; contrast 2 and 3: all p > 0.23). However, sea stars showed a strong negative response to PAR. On average, sea stars in shade treatments spent $>67 \%$ of their time under the filters (Fig. 3, Table 1; contrast 4, effect of PAR; both $\mathrm{p} \leq 0.002$ ).
Table 1. Analysis of the proportion of time spent by Pisaster ochraceus under treatment filters during experimental trials. Data are the untransformed percent of observations in which the sea stars were located entirely underneath experimental filters (or, in no-filter controls, percent observations on a randomly determined side of the tank). ANOVA for animals fed 24 and $72 \mathrm{~h}$ before the start of the experiment; $\mathrm{n}=5$ blocks, 10 replicates block ${ }^{-1}$ for each regime. Hypotheses were tested using a series of a priori contrasts (see 'Materials and methods: Data collection and analysis'). Bold indicates significance at the $\alpha=0.05$ level

\begin{tabular}{|c|c|c|c|c|}
\hline & df & SS & $F$ & $\mathrm{p}$ \\
\hline \multicolumn{5}{|l|}{$\underline{24 \mathrm{~h} \text { feeding regime }}$} \\
\hline Treatment & 4 & 1.13 & 7.97 & 0.0003 \\
\hline Block & 4 & 0.09 & 0.67 & 0.6224 \\
\hline Treatment $\times$ Block & 16 & 0.34 & 0.59 & 0.8950 \\
\hline Error & 25 & 0.89 & & \\
\hline $\begin{array}{l}\text { Contrasts } \\
\text { (1) Effect of filter } \\
\text { No-filter control vs. filter control } \\
\text { (+UVB +UVA +PAR) vs. (+UVB +UVA +PAR) }\end{array}$ & 1 & 0.48 & 1.35 & 0.2556 \\
\hline $\begin{array}{l}\text { (2) Effect of UVB } \\
\text { Filter control vs. no UVB } \\
\text { (+UVB +UVA +PAR) vs. (-UVB +UVA +PAR) }\end{array}$ & 1 & 0.04 & 1.03 & 0.3198 \\
\hline $\begin{array}{l}\text { (3) Effect of UVA } \\
\text { No UVB vs. no UVR } \\
\text { (-UVB +UVA +PAR) vs. (-UVB -UVA +PAR) }\end{array}$ & 1 & 0.05 & 1.47 & 0.2364 \\
\hline $\begin{array}{l}\text { (4) Effect of PAR } \\
\text { No UVR vs. shade } \\
\text { (-UVB -UVA +PAR) vs. (-UVB -UVA -PAR) }\end{array}$ & 1 & 0.45 & 12.71 & 0.002 \\
\hline \multicolumn{5}{|l|}{$\underline{72 \mathrm{~h} \text { feeding regime }}$} \\
\hline Treatment & 4 & 0.36 & 10.69 & $<0.0001$ \\
\hline Block & 4 & 0.03 & 0.94 & 0.4566 \\
\hline Treatment $\times$ Block & 16 & 0.19 & 1.42 & 0.2083 \\
\hline Error & 25 & 0.21 & & \\
\hline $\begin{array}{l}\text { Contrasts } \\
\text { (1) Effect of filter } \\
\text { No-filter control vs. filter control } \\
\text { (+UVB +UVA +PAR) vs. (+UVB +UVA +PAR) }\end{array}$ & 1 & 0.007 & 0.83 & 0.3710 \\
\hline $\begin{array}{l}\text { (2) Effect of UVB } \\
\text { Filter control vs. no UVB } \\
\text { (+UVB +UVA +PAR) vs. (-UVB +UVA +PAR) }\end{array}$ & 1 & 0.001 & 0.13 & 0.7261 \\
\hline $\begin{array}{l}\text { (3) Effect of UVA } \\
\text { No UVB vs. no UVR } \\
\text { (-UVB +UVA +PAR) vs. (-UVB -UVA +PAR) }\end{array}$ & 1 & 0.009 & 1.03 & 0.3211 \\
\hline $\begin{array}{l}\text { (4) Effect of PAR } \\
\text { No UVR vs. shade } \\
\text { (-UVB -UVA +PAR) vs. (-UVB -UVA -PAR) }\end{array}$ & 1 & 0.150 & 17.65 & 0.0003 \\
\hline
\end{tabular}

Each block of the experiment was carried out on a separate day, and therefore the intensity of solar radiation varied naturally among blocks despite the fact that they were all carried out in similar conditions (sunny days with clear skies). There is no evidence that the behavior of the sea stars changed in response to this environmental variation. The percentage of time spent under the filters did not differ among blocks for either feeding regime (Table 1 ; block effect, both $\mathrm{p}>0.45$ ). Similarly, the effect of our filter treatments was consistent across blocks for both feeding regimes (Table 1 ; 


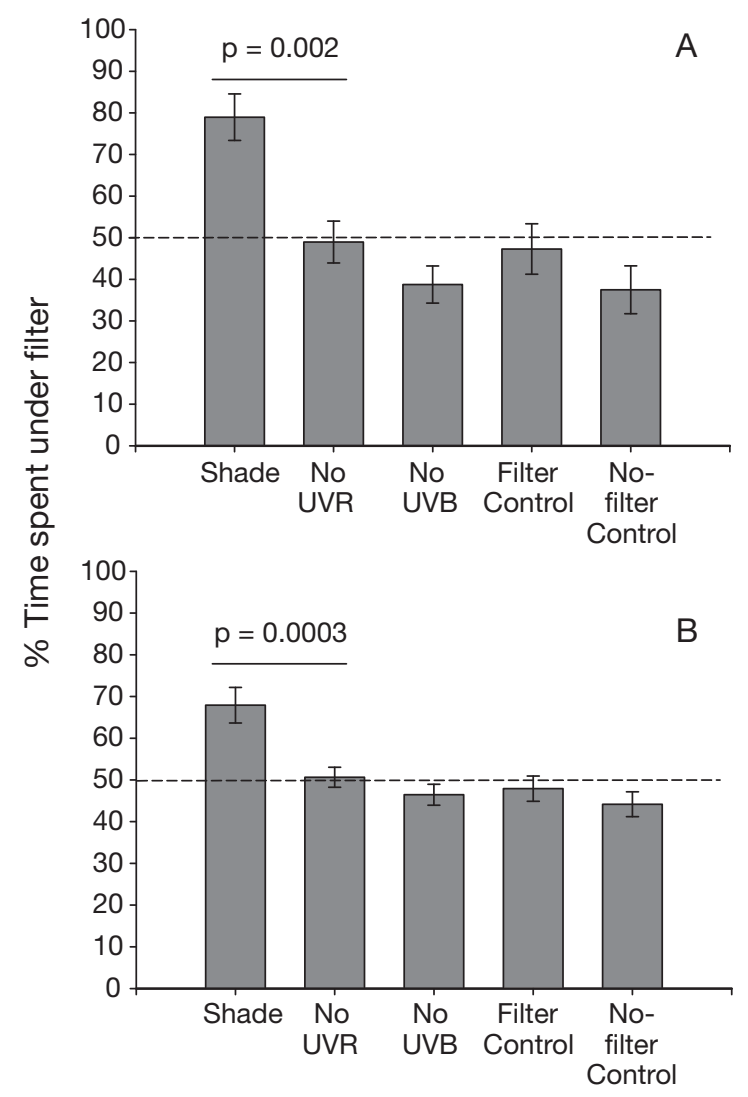

Fig. 3. Pisaster ochraceus microhabitat choice in experimental tanks. (A) $24 \mathrm{~h}$ and (B) $72 \mathrm{~h}$ feeding regime. Data are mean \pm standard error of the mean (SEM) percent of observations in which sea stars were under experimental filter or, for no-filter controls, on a randomly determined side of the tank. For each feeding regime, $\mathrm{n}=10$ ind. treatment ${ }^{-1}$. Dashed line indicates no microhabitat choice; because filters covered $50 \%$ of each treatment tank, individuals that spent $50 \%$ of their time under the filter did not respond to the treatment. Labels refer to experimental treatments (see 'Materials and methods' and Fig. 1). Shade $=-U V B-U V A-P A R$. No UVR $=-U V B-U V A$ $+\mathrm{PAR}$. No UVB $=-\mathrm{UVB}+\mathrm{UVA}+\mathrm{PAR}$. Filter control $=+\mathrm{UVB}$ $+\mathrm{UVA}+\mathrm{PAR}$. No-filter control $=+\mathrm{UVB}+\mathrm{UVA}+\mathrm{PAR}$. P. ochraceus responded to light treatments (ANOVA, $\mathrm{p} \leq 0.0003$ for both feeding regimes). Treatment effects were evaluated with a priori pairwise contrasts; significant differences are indicated by bars above the contrasted treatments with the relevant $\mathrm{p}$-value

block $\times$ treatment effect, both $\mathrm{p}>0.20$ ). Still, to assess the effect of natural variation in UVR levels on a finer scale, we examined the relationship between the amount of time individuals spent under filters in the 2 total UVR removal treatments (no UVR and shade) and the intensity of UV radiation on the day of the experiment for the sea stars in the $72 \mathrm{~h}$ feeding regime (tested in 2006). (As we were not able to measure radiation intensity during the 2005 experiments, we were not able to do this analysis for the $24 \mathrm{~h}$ feeding regime.) The average integrated intensity of solar radiation dur- ing the $72 \mathrm{~h}$ feeding regime blocks ranged from 519 to $545 \mathrm{~W} \mathrm{~m}^{-2}$. There was no evidence that the amount of time spent by sea stars in the no-UVR (-UVB -UVA $+\mathrm{PAR})$ and shade (-UVB -UVA - PAR) treatments was related either to the intensity of UVB during the experiment (correlation analysis, $\mathrm{n}=20$ sea stars on $5 \mathrm{~d}, \mathrm{r}=-0.147, \mathrm{p}=0.59$ ) or to the intensity of UVA during the experiment (correlation analysis, $\mathrm{n}=20$ sea stars on $5 \mathrm{~d}, \mathrm{r}=0.002, \mathrm{p}=0.99$ ).

Individuals in all treatments were active throughout the experimental trial period. When sea stars were fed $24 \mathrm{~h}$ before the start of the experiment, individuals in the +PAR treatments (no-filter controls, filter controls, no UVB, and no UVR) shifted locations in the tank on average $( \pm \mathrm{SD}) 16.52 \pm 6.36$ times during the $4 \mathrm{~h}$ experiment ( $\mathrm{n}=40$ individuals). Sea stars fed $72 \mathrm{~h}$ before the start of the experiment showed similar levels of activity: individuals in the $4+\mathrm{PAR}$ treatments shifted positions an average of $18.05 \pm 4.07$ times over $4 \mathrm{~h}$ ( $\mathrm{n}=40$ individuals). For both feeding regimes, individuals in the shade treatment switched positions fewer times than the animals in the +PAR treatments. In the $24 \mathrm{~h}$ feeding regime, the shade treatment sea stars switched positions on average $8.9 \pm 6.47$ times ( $\mathrm{n}=10$ individuals). Similarly, in the $72 \mathrm{~h}$ feeding regime, individuals in the shade treatment shifted positions an average of $12.6 \pm$ 3.62 times over $4 \mathrm{~h}$ ( $\mathrm{n}=10$ individuals).

\section{Microhabitat location in the field}

At low tide, Pisaster ochraceus individuals are only rarely positioned in unshaded areas. Emersed individuals encountered at low tide were not evenly distributed among microhabitats (Fig. 4; chi-square goodness of fit test, $\left.\chi^{2}=342.4, p<0.001\right)$. Overall, $85 \%$ of emersed individuals were entirely shaded from solar radiation, either by rocks or by kelp. Another $6 \%$ of encountered individuals were partially shaded, leaving only $9 \%$ of emersed individuals (25 of 283 observations) that were fully exposed to sunlight at low tide.

Shaded microhabitats had lower levels of UVR than unshaded areas at low tide. Counting both emersed individuals and individuals in shallow water, a total of 182 sea stars were found in areas shaded by rocks (in crevices in the rocky benches or underneath overhanging rocks). UVB radiation in these habitats is on average $( \pm \mathrm{SD}) 10.5 \pm 8.02 \%$ of the intensity in the open ( $\mathrm{n}=7$ independent in situ measurements on $2 \mathrm{~d}$ during summer 2005) and UVA intensity is on average $22.2 \pm 5.26 \%$ of the intensity in the open (n as for UVB measurements). A total of 116 Pisaster ochraceus individuals were found under brown algae at low tide: $86 \%$ of these individuals were found under the stipeless kelp Hedophyllum sessile. Under H. sessile, UVB 


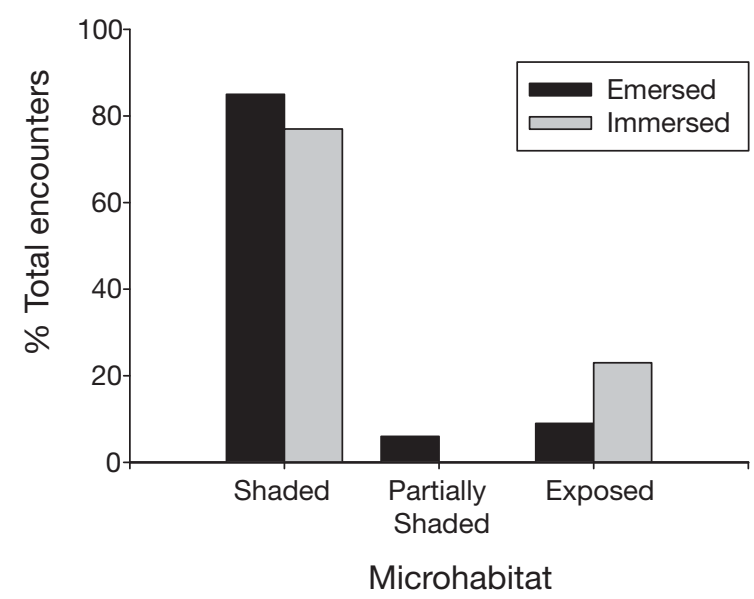

Fig. 4. Pisaster ochraceus microhabitat location in field surveys. Low-tide surveys were conducted on $15 \mathrm{~d}$ in summer 2005. Emersed individuals $(n=283)$ were not covered by water at low tide; immersed individuals $(\mathrm{n}=91)$ were covered by water (either in intertidal tidepools or $<0.5 \mathrm{~m}$ from the surface of the water at the waterline). Data are percent of total observations of sea stars

intensity was on average $0.43 \pm 0.57 \%$ of the intensity in unshaded areas (Fig. 2; integrated measurement of intensity from 300 to $315 \mathrm{~nm}$, LiCor 1800-UW Spectroradiometer, $\mathrm{n}=6$ thalli over $2 \mathrm{~d}$ in 2006). UVA intensities under the $H$. sessile canopy were on average $0.48 \pm 0.51 \%$ of intensities in unshaded areas ( $\mathrm{n}$ as for UVB measurements).

Pisaster ochraceus remaining in water during low tides were not evenly distributed among habitats (chisquare goodness of fit test, $\chi^{2}=26.4$, $p<0.001$ ). Seventy-seven percent of individuals that were found in water during low tide were completely shaded from solar radiation (70 of 91 observations). The remaining $23 \%$ of individuals in shallow water were fully exposed to sunlight.

\section{DISCUSSION}

In shallow-water conditions, Pisaster ochraceus did not respond to ambient levels of UVB or UVA, but did actively avoid areas with ambient levels of PAR by moving into shaded microhabitats. If we include time spent at the midline (in partial shade), sea stars in the shade treatment spent an average $( \pm$ SD) of $82 \pm 13.8 \%$ of their time either fully or partially shaded from solar radiation. One-quarter of the individuals in the shade treatment never moved fully into the unshaded portion of the tank, but spent an average of $5.0 \pm 4.31 \%$ of their time at the tank midline partially exposed to sunlight. At the midline they would extend an arm beyond the filter into the open half of the tank then move back under the shade. This behavior was not exhibited by sea stars in any of the other filter treatments. Three-quarters of the individuals in the shade treatment moved fully into the unshaded portion of the tank for short periods of time. In each case, they would emerge into the open side of the tank, move steadily to the end of the tank, and immediately reverse direction to return to the shade. Sea stars in the shade treatment repeatedly chose to move into the shaded area of the tank after experiencing conditions in the area outside the shades. Hunger level did not seem to substantially affect sea star movement patterns. Although individuals in the 72 $\mathrm{h}$ feeding regime moved slightly more than those in the $24 \mathrm{~h}$ feeding regime, 'hungry' sea stars still spent on average almost $70 \%$ of their time in the shade (Fig. 3).

We are confident that the sea stars were responding to differences in light conditions created by treatment filters because other abiotic conditions were not detectably different among treatments. Water temperature of our experimental tanks was well within the range that Pisaster ochraceus experiences in the field. In the summer in the San Juan Islands, intertidal hightide water temperatures range from 10.5 to $13^{\circ} \mathrm{C}$ (J. L. Burnaford unpubl. data and http://140.142.199.7/ vdv/VV_Frame.php). P. ochraceus in tidepools during sunny low tides experience temperatures exceeding $20^{\circ} \mathrm{C}$ (J. L. Burnaford unpubl. data). Although conditions under shade treatment filters were slightly cooler than in the open side of the tank, the difference was $<0.5^{\circ} \mathrm{C}$ and almost identical to the temperature reduction of the no-UVR treatment filters. If sea stars were responding to minute temperature differences within tanks we would have seen a response in the no-UVR treatment, but we did not.

Studies in aquatic systems have led to an increasing number of examples of organisms that exhibit behavioral responses to UVR. Exposure to UVB has been shown to reduce motility in phytoplankton (e.g. Richter et al. 2007) and macroalgal 'swarmers' (Flores-Moya et al. 2002). Many invertebrates alter their movement patterns in ways that allow them to avoid UVR (reviewed in Roy 2000, Leech \& Johnsen 2003). Freshwater cladocerans (Leech \& Williamson 2001) and barnacle nauplii (Chiang et al. 2007) specifically avoid UVB by moving deeper in the water column when UVB radiation shines on the water surface. Other organisms respond only to the longer UVR wavelengths; e.g. Antarctic krill move deeper in the water column in response to UVA, but not to UVB (Newman et al. 2003). Focusing specifically on the phylum Echinodermata, 2 species of sea urchins (Paracentrotus lividus [Verling et al. 2002] and Strongylocentrotus droebachiensis [Adams 2001, Dumont et al. 2007]) cover themselves with shade-producing materials in response to exposure to UVR, but not in response to PAR. Given these results and the known harmful 
effects of UVR for organisms, we were surprised that the sea stars did not respond to either UVA or UVB. We consider 3 (not mutually exclusive) possibilities for their lack of response to UVR: (1) they may be physiologically protected from UVR-induced damage, (2) they may possess the ability to repair UVR-induced damage, and (3) they may lack the neurological capacity to detect UVR.

A variety of molecules can protect organisms from damage from UVR exposure. Mycosporine-like amino acids (MAAs), which absorb UVR wavelengths, have been found in many taxa including echinoid echinoderms (Shick \& Dunlap 2002, Hader et al. 2007). Antioxidant carotenoids, which protect cells from reactive oxygen species (Edge et al. 1997), reduce damage from UVR exposure in sea urchin embryos (Lamare \& Hoffman 2004). Alternatively, many organisms are able to tolerate exposure to UVR because they are able to efficiently detect and repair cellular damage and DNA mutations (Sinha \& Hader 2002, Hader \& Sinha 2005). Determining whether Pisaster ochraceus possess any of these protective molecules or repair processes is a subject for future research.

Perhaps the most likely reason that Pisaster ochraceus responds to PAR but not UVA or UVB is that they are unable to detect UVR wavelengths. Asteroids have 2 mechanisms for light detection: clusters of photosensory cells (ocelli) at the arm tips and individual sensory cells scattered through the epidermis (Ruppert et al. 2004). To our knowledge, no studies have quantified the detection limits of $P$. ochraceus photosensory cells. The ocelli of the sea star Asterias amurensis are stimulated by wavelengths in the PAR range (Yoshida \& Ohtsuki 1966). If this is a general pattern of the class Asteroidea, it may explain the lack of response by $P$. ochraceus to UVR.

If Pisaster ochraceus cannot detect UVR, they are not alone. Several studies have identified organisms that fail to show behavioral responses to UVR (e.g. Damkaer \& Dey 1982, Speekmann et al. 2000, Richter et al. 2007). Functionally, avoiding PAR may allow an organism to avoid a suite of potentially dangerous abiotic and biotic variables. Areas with low levels of PAR may have lower temperatures, lower levels of desiccation, lower levels of UVR, and a lower risk of predation from visual predators than areas with high levels of PAR. Gulls and sea otters (both visual predators) are known to consume P. ochraceus (Harley et al. 2006, Snellen et al. 2007) and it is possible that avoiding PAR reduces predation pressure on the sea star. However, because overall rates of predation on $P$. ochraceus appear to be extremely low (Harley et al. 2006, Snellen et al. 2007, J. L. Burnaford pers. obs., B. A. Menge pers. comm.), the physiological consequences of shade-seeking behavior may be of greater importance for this species.
Despite these potential benefits of using PAR as a habitat selection cue, the use of only PAR (from among the entire spectrum of solar radiation) has important implications for organisms. Worldwide ozone levels are decreasing (UNEP 2007) and UVB levels are increasing in temperate as well as polar regions (Kerr \& McElroy 1993, Madronich et al. 1998). As the ratio of UVB to PAR increases in response to ozone depletion, organisms that use PAR as a cue to avoid 'dangerous' environmental conditions will likely experience increasing amounts of damage from UVR because they will not seek shelter even under high-UVB conditions (Roy 2000). On a shorter time scale, the use of PAR as a cue for habitat choice can have limitations because areas of low PAR are not necessarily always 'safe' habitats. Materials that block PAR but absorb and reradiate heat may provide environments that are shady but still outside of the organism's optimal temperature range. Because of differences in canopy architecture and optical properties of different species of plants and algae, 2 understory areas with equal low amounts of PAR may have substantially different levels of UVR (e.g. Brown et al. 1994, Beach et al. 2006). Experiencing even low levels of these abiotic stressors can be metabolically costly; for example, exposure to sublethal levels of UVR has been shown to increase oxygen consumption rates in marine amphipods (Obermuller et al. 2007). Therefore, the specific properties of available shade-producing materials could have important effects for an organism.

At our field site there are 2 major categories of shade-producing materials: rock (overhangs, crevices, and boulders) and kelp. The kelps include species with a stipe (Egregia menziesii, Nereocystis leutkeana, Laminaria spp., and Alaria marginata) and 1 species without a stipe (Hedophyllum sessile). Because the stiped kelps move with the water as the tide drops, some of the animals in their shade in shallow water may become exposed to full sunlight for the duration of the low tide. In contrast, the stipeless $H$. sessile has broad blades that arise directly from the holdfast, and the area shaded by the thallus does not change substantially between high and low tide. For organisms that choose locations as the tide drops, rock overhangs and $H$. sessile thalli should therefore provide more reliably shady microhabitat conditions than stiped kelps.

Conditions in these shady areas under rocks or Hedophyllum sessile during low tide are very different from conditions on exposed rock surfaces. At our site in summer 2005, low-tide temperatures under $H$. sessile or rock outcrops were on average $9.5^{\circ} \mathrm{C}$ cooler than temperatures in unshaded areas (J. L. Burnaford unpubl. data). Both habitats have substantially lower levels of UVR than open areas; in fact, the area under an $H$. sessile canopy is exposed to less solar radiation 
than the area beneath a rocky outcrop. The most likely explanation for this difference is the morphology of the alga. The margins of $H$. sessile blades touch the rock surface, protecting understory organisms from direct and reflected radiation, whereas a rocky overhang will not protect an organism from reflected light. At our field site, with available rock overhangs and abundant $H$. sessile, it appears that the negative response of Pisaster ochraceus to PAR allows most individuals to identify habitats that also have low temperatures and low levels of UVR. This could mean that most of the $P$. ochraceus in the intertidal zone at low tide do not incur substantial metabolic costs during emersion.

As predators, Pisaster ochraceus have significant effects on community structure and function (Mauzey 1966, Paine 1966, Menge 1972). Understanding the sea star's behavioral responses to environmental conditions can help us to more fully understand their impacts on their prey items and subsequently their impacts on the structure of intertidal communities. If avoiding PAR causes individuals to remain in shaded microhabitats at high tide, predation pressures might consequently be stronger in shaded habitats than in open areas. For intertidal organisms on lower trophic levels this would create an interesting ecological conflict, as shaded areas that provide a suite of physiological benefits at low tide would be the areas of the highest risk of mortality from predation at high tide. In areas with available rock outcrops or high cover of canopy-forming algae like Hedophyllum sessile, $P$. ochraceus may be able to remain in the intertidal zone during low tides without incurring significant physiological damage, and this could potentially lead to differences in predator impacts between sites. The negative behavioral response of $P$. ochraceus to PAR in shallow-water conditions therefore has the potential to create patchy predation pressure on both small (within a site) and large (among sites) spatial scales. The effect of the sea star on the community at any 1 location may be more greatly influenced by the abiotic conditions and the physical structure of the habitat than we have previously thought.

Acknowledgements. The authors are grateful to A. O. D. Willows, K. Sebens, S. Schwinge, and the University of Washington FHL for providing laboratory space and logistical support for this research and to B. and S. Ragen for providing access to our field site at Pile Point. L. Fly, S. Henderson, C. Pennington, and A. Showalter helped with field surveys and animal collection. L. B. Bybee, C. Staude, and A. Cairns gave technical assistance for the LiCor spectroradiometer. R. Strathmann and J. Hoffman donated light-filtering materials. Comments by B. Pernet, E. Iyengar, and 3 anonymous reviewers improved the manuscript. Funding was provided by the Blinks Fellowship Program at FHL (J.L.B. and M.V.) and a Sigma Xi Summer Research Grant (M.V.).

\section{LITERATURE CITED}

Adams NL (2001) UV radiation evokes negative phototaxis and covering behavior in the sea urchin Strongylocentrotus droebachiensis. Mar Ecol Prog Ser 213:87-95

Apprill AM, Lesser MP (2003) Effects of ultraviolet radiation on Laminaria saccharina in relation to depth and tidal height in the Gulf of Maine. Mar Ecol Prog Ser 256:75-85

> Beach KS, Borgeas HB, Smith CM (2006) Ecophysiological implications of the measurement of transmittance and reflectance of tropical macroalgae. Phycologia 45:450-457

Brown MJ, Parker GG, Posner NE (1994) A survey of ultraviolet-B radiation in forests. J Ecol 82:843-854

> Burnaford JL (2004) Habitat modification and refuge from sublethal stress drive a marine plant-herbivore association. Ecology 85:2837-2849

Chiang WL, Wu RSS, Yu PKN, Au DWT (2007) Are barnacle larvae able to escape from the threat of UV? Mar Biol 151:703-711

Damkaer DM, Dey DB (1982) Short-term response of some planktonic crustacea exposed to enhanced UV-B radiation. In: Calkins J (ed) The role of solar ultraviolet radiation in marine ecosystems. Plenham Press, New York, p 417-427

Dumont CP, Drolet D, Deschenes I, Himmelman JH (2007) Multiple factors explain the covering behaviour in the green sea urchin, Strongylocentrotus droebachiensis. Anim Behav 73:979-986

Edge R, McGarvey D, Truscott T (1997) The carotenoids as anti-oxidants - a review. J Photochem Photobiol B 41: $189-200$

> Flores-Moya A, Posudin YI, Fernandez JA, Figueroa FL, Kawai H (2002) Photomovement of the swarmers of the brown algae Scytosiphon lomentaria and Petalonia fascia: effect of photon irradiance, spectral composition and UV dose. J Photochem Photobiol B 66:134-140

Gleason DF, Edmunds PJ, Gates RD (2006) Ultraviolet radiation effects the behavior and recruitment of larvae from the reef coral Porites astreoides. Mar Biol 148:503-512

Hader DP, Sinha RP (2005) Solar ultraviolet radiation-induced DNA damage in aquatic organisms: potential environmental impact. Mutat Res 571:221-233

Hader DP, Kumar HD, Smith RC, Worrest RC (2007) Effects of solar UV radiation on aquatic ecosystems and interactions with climate change. Photochem Photobiol Sci 6:267-285

Harley CDG, Pankey MS, Wares JP, Grosberg RK, Wonham MJ (2006) Color polymorphism and genetic structure in the sea star Pisaster ochraceus. Biol Bull 211:248-262

Helmuth BST, Hofmann GE (2001) Microhabitats, thermal heterogeneity, and patterns of physiological stress in the rocky intertidal zone. Biol Bull 201:374-384

Hoffman JR, Hansen LJ, Klinger T (2003) Interactions between UV radiation and temperature limit inferences from single-factor experiments. J Phycol 39:268-272

Johnsen S, Kier WM (1998) Damage due to solar ultraviolet radiation in the brittlestar Ophioderma brevispinum (Echinodermata: Ophiuroidea). J Mar Biol Assoc UK 78: 681-684

Kelly DJ, Bothwell ML (2002) Avoidance of solar ultraviolet radiation by juvenile coho salmon (Oncorhynchus kisutch). Can J Fish Aquat Sci 59:474-482

Kerr JB, McElroy CT (1993) Evidence for large upward trends of ultraviolet-B radiation linked to ozone depletion. Science 262:1032-1034

> Lamare MD, Hoffman J (2004) Natural variation of carotenoids in the eggs and gonads of the echinoid genus, Strongylocentrotus: implications for their role in ultravio- 
let radiation photoprotection. J Exp Mar Biol Ecol 312: 215-233

Leech DM, Johnsen S (2003) Behavioral responses-UVR avoidance and vision. In: Helbling EW, Zagarese H (eds) UV effects in aquatic organisms and ecosystems. Royal Society of Chemistry, Cambridge, p 455-484

Leech DM, Williamson CE (2001) In situ exposure to ultraviolet radiation alters the depth distribution of Daphnia. Limnol Oceanogr 46:416-420

Lesser MP (2006) Oxidative stress in marine environments: biochemistry and physiological ecology. Annu Rev Physiol 68:253-278

Lesser MP, Barry TM (2003) Survivorship, development, and DNA damage in echinoderm embryos and larvae exposed to ultraviolet radiation (290-400 nm). J Exp Mar Biol Ecol 292:75-91

Lobban CS, Harrison PJ (1994) Seaweed ecology and physiology. Cambridge University Press, Cambridge

Madronich S, McKenzie RL, Bjorn LO, Caldwell MM (1998) Changes in biologically active ultraviolet radiation reaching the Earth's surface. J Photochem Photobiol B 46:5-19

Mauzey KP (1966) Feeding behavior and reproductive cycles in Pisaster ochraceus. Biol Bull 131:127-144

> Menge BA (1972) Competition for food between two intertidal starfish species and its effect on body size and feeding. Ecology 53:635-644

Menge BA, Berlow EL, Blanchette CA, Navarrete SA, Yamada SB (1994) The keystone species concept: variation in interaction strength in a rocky intertidal habitat. Ecol Monogr 64:249-286

> Newman SJ, Ritz DR, Nicol S (2003) Behavioural reactions of Antarctic krill (Euphausia superba Dana) to ultraviolet and photosynthetically active radiation. J Exp Mar Biol Ecol 297:203-217

Obermuller B, Puntarulo S, Abele D (2007) UV-tolerance and instantaneous physiological stress responses of two Antarctic amphipod species Gondogeneia antarctica and Djerboa furcipes during exposure to UV radiation. Mar Environ Res 64:267-285

Paine RT (1966) Food web complexity and species diversity. Am Nat 100:65-75

Przeslawski R, Davis AR, Benkendorff K (2004) Effects of ultraviolet radiation and visible light on the development

Editorial responsibility: Hans Heinrich Janssen,

Oldendorf/Luhe, Germany of encapsulated molluscan embryos. Mar Ecol Prog Ser 268:151-160

Richter PR, Hader DP, Goncalves RJ, Marcoval MA, Villafane VE, Helbling EW (2007) Vertical migration and motility responses in three marine phytoplankton species exposed to solar radiation. Photochem Photobiol 83:810-817

Roy S (2000) Strategies for the minimisation of UV-induced damage. In: deMora S, Demers $\mathrm{S}$, Vernet $\mathrm{M}$ (eds) The effects of UV radiation in the marine environment. Cambridge University Press, Cambridge, p 177-205

Ruppert EE, Fox RS, Barnes RD (2004) Invertebrate biology: a functional evolutionary approach. Brooks/Cole, Toronto

Shick JM, Dunlap WC (2002) Mycosporine-like amino acids and related gadusols: biosynthesis, accumulation, and UV-protective functions in aquatic organisms. Annu Rev Physiol 64:223-262

Sinha RP, Hader DP (2002) UV-induced DNA damage and repair: a review. Photochem Photobiol Sci 1:225-236

Snellen CL, Hodum PJ, Fernandez-Juricic E (2007) Assessing western gull predation on purple sea urchins in the rocky intertidal using optimal foraging theory. Can J Zool 85: 221-231

Speekmann CL, Bollens SM, Avent SR (2000) The effect of ultraviolet radiation on the vertical distribution and mortality of estuarine zooplankton. J Plankton Res 22: 2325-2350

Tedetti M, Sempere R (2006) Penetration of ultraviolet radiation in the marine environment: a review. Photochem Photobiol 82:389-397

UNEP (United Nations Environment Programme) (2007) Scientific assessment of ozone depletion: 2006. Executive summary. World Meteorological Organization Global Ozone Research and Monitoring Project, Geneva

Verling E, Crook AC, Barnes DKA (2002) Covering behaviour in Paracentrotus lividus: Is light important? Mar Biol 140:391-396

Xenopoulos MA, Schindler DW (2001) Physical factors determining ultraviolet radiation flux into ecosystems. In: Cockell CS, Blaustein AR (eds) Ecosystems, evolution, and ultraviolet radiation. Springer-Verlag, New York, p 36-62

Yoshida M, Ohtsuki H (1966) Compound ocellus of a starfish: its function. Science 153:197-198

Zamzow JP (2004) Effects of diet, ultraviolet exposure, and gender on the ultraviolet absorbance of fish mucus and ocular structures. Mar Biol 144:1057-1064

Submitted: October 22, 2007; Accepted: June 4, 2008

Proofs received from author(s): September 15, 2008 